\title{
The Sendai Framework for Disaster Risk Reduction at Five: Lessons from the 2011 Great East Japan Earthquake and Tsunami
}

\author{
Elizabeth Maly $^{1} \cdot$ Anawat Suppasri $^{1}$
}

Published online: 20 April 2020

(C) The Author(s) 2020

\begin{abstract}
The Sendai Framework for Disaster Risk Reduction 2015-2030 (SFDRR) represents an inclusive approach to disaster risk reduction, linked to development and recovery. Building on previous international guidelines, the SFDRR promotes practical and measurable outcomes for reducing disaster losses, including indicators to measure progress towards seven specific global targets. Evaluated in the context of the priorities and global targets of the SFDRR, the article considers the case of the Great East Japan Earthquake and Tsunami of 2011 to illustrate advances and limitations in pre-disaster tsunami hazard engineering and post-disaster recovery. With respect to the targets set out in the Sendai Framework related to risk reduction and tsunami engineering, especially Priority 1 , understanding disaster risk, there have been significant advances in hazard assessment and systems for tsunami detection and warning. Although the SFDRR emphasizes actions in the recovery phase through Priority 4, enhancing disaster preparedness with an emphasis on the concept of build back better, on its own this does not function as a clear directive for guiding recovery. However, the overall people-centered and inclusive approach of the SFDRR, as well as the global targets and several sub-priorities, can be a useful way to shape good practices in recovery and evaluate recovery progress.
\end{abstract}

Keywords Build back better - Disaster recovery - Great East Japan Earthquake $\cdot$ Sendai Framework - Tsunami risk

Elizabeth Maly

maly@irides.tohoku.ac.jp

1 International Research Institute of Disaster Science, Tohoku University, Sendai 980-8579, Japan

\section{Introduction}

On 11 March 2011, the Mw 9.0 Great East Japan Earthquake (GEJE) struck off Japan's northeast Tohoku coast. The massive tsunami that resulted took the lives of more than 18,000 people on that day, and indirectly led to the deaths of more than 3000 additional victims (National Police Agency 2019; Reconstruction Agency 2019b). More than 400,000 houses were destroyed (National Police Agency 2019) in communities along a $500 \mathrm{~km}$ coastline. The nuclear meltdown at the Fukushima Daiichi Nuclear Power Plant caused widespread and long-term displacement and uncertainty, and unprecedented complexity for the response and recovery. In the days following the tsunami 470,000 people evacuated from their homes. As of December 2019, close to 50,000 people were still displaced (Reconstruction Agency 2019b).

Adopted in March 2015 at the 3rd United Nations Conference for Disaster Risk Reduction in Sendai, the largest city in the GEJE-affected area, the Sendai Framework for Disaster Risk Reduction 2015-2030 (SFDRR) (UNISDR 2015) became the international guiding instrument for disaster risk reduction (DRR). It succeeded the Hyogo Framework for Action 2005-2015: Building the Resilience of Nations and Communities to Disasters (HFA) (UNISDR 2015), which had developed from previous efforts to strengthen investment in disaster prevention, including the 1994 Yokohama Strategy and Plan of Action for a Safer World: Guidelines for Natural Disaster Prevention, Preparedness, and Mitigation (IDNDR 1994) created as the midterm review of the International Decade for Natural Disaster Reduction (IDNDR) 1989-1999.

This growing international commitment to DRR over several decades is a response to devastating disaster impacts, such as the loss of over 200,000 lives after the 
2004 Indian Ocean (Boxing Day) Tsunami, which raised awareness of the need for international collaboration for DRR. Other disasters that have drawn attention to the urgency of implementing the Hyogo Framework's principles included Hurricane Katrina (2005), the Great East Japan Earthquake (2011), and Typhoon Yolanda (international name: Haiyan) in the Philippines (2013) (AitsiSelma et al. 2015).

Reflecting Japan's long history of disaster experience and commitment to DRR (Cabinet Office 2015) all three world conferences on disasters were held in Japan. The 1st World Conference on Natural Disasters in Yokohama (1994) led to the Yokohama Strategy (IDNDR 1994). The 2nd World Conference on Disaster Reduction (2005) in Kobe City, Hyogo Prefecture, 10 years after the 1995 Great Hanshin Awaji Earthquake, resulted in the Hyogo Framework. The 3rd World Conference on Disaster Reduction (2015) in Sendai followed years of devastating disasters including: earthquakes in Gujarat (2001), Bam (2003), Kashmir (2005), Sichuan (2008), and Haiti (2010); Cyclone Nargis in Myanmar (2008); and tsunamis in the Indian Ocean (2004) and after the Great East Japan Earthquake (2011).

In response to this overwhelming damage and with the mission to actively reduce future losses, the SFDRR builds on previous DRR guidelines while departing from them in several significant aspects. (1) The SFDRR focuses on practical and measurable outcomes for reducing disaster losses, including indicators to measure progress towards seven specific global targets. (2) The SFDRR strongly emphasizes a localized and people-centered approach and inclusivity of all people in disaster prevention and response processes, with sensitivity to gender, age, (dis)ability, and indigenous and vulnerable populations. (3) The SFDRR supports crosscutting issues and mainstreaming DRR and an approach that links disaster prevention, response, recovery, and development needs. (4) The idea of resilience in recovery features prominently in Priority 4 , with a call to "Build Back Better" in recovery, rehabilitation, and reconstruction. (5) The SFDRR specifically mentions several key issues: climate change and development; education and health; and biological and technological disasters, as well as disasters resulting from natural hazard events.

The seven global targets of the SFDRR, including numerical goals and timelines for achievement, can be summarized as follows:

(a) Substantially reduce global disaster mortality;

(b) Substantially reduce the number of affected people globally;

(c) Reduce direct disaster economic loss; (d) Substantially reduce disaster damage to critical infrastructure and disruption of basic services, among them health and educational facilities;

(e) Substantially increase the number of countries with disaster risk reduction strategies;

(f) Substantially enhance international cooperation with developing countries;

(g) Substantially increase the availability of, and access to, multi-hazard early warning systems and disaster risk information and assessments to the people (UNISDR 2015).

Towards these seven targets, the SFDRR includes four priorities for action:

Priority 1. Understanding disaster risk;

Priority 2. Strengthening disaster risk governance to manage disaster risk;

Priority 3. Investing in disaster risk reduction for resilience;

Priority 4. Enhancing disaster preparedness for effective response and to "Build Back Better" in recovery, rehabilitation and reconstruction (UNISDR 2015).

Emphasizing people-centered and community-based approaches, the Sendai Framework represents a significant shift toward an inclusive all-of-society perspective that recognizes the importance of awareness of the needs of society's poorest members, along with integrating "a gender, age, disability and cultural perspective in all policies and practices" (UNISDR 2015, p. 13). Building on previous guidelines, the SFDRR reflects new approaches and roles for practical disaster science to reduce risks in quantifiable ways with objective targets. Although the underlying mandate of the SFDRR is risk reduction to reduce damage, recovery features prominently in Priority 4, where strong connections are made between DRR, recovery, and development. As the scope and purpose states, the Sendai Framework "aims to guide the multihazard management of disaster risk in development at all levels as well as with and across all sectors" (UNISDR 2015, p. 11).

\section{Objective and Methodology}

Nine years after the Great East Japan Earthquake, recovery is ongoing for communities across wide and varied areas in the Tohoku region. Drawing on past precedents, current reconstruction projects and processes will have major longterm impacts on the region and offer valuable lessons for future recovery programs. Drawing on past events and previous knowledge, the GEJE showed the limitations of 
tsunami engineering for hazard mitigation and led to engineering advances. At the same time, subsequent tsunamis have highlighted the limitations that still exist. Considered in the context of the SFDRR five years after it was adopted as the main international DRR guideline, this article focuses on examples of experiences after the GEJE from the standpoints of (1) pre-disaster tsunami hazard risk and (2) post-disaster recovery and vulnerability.

Lessons from the GEJE include various engineering measures for improved tsunami warning and observation, mapping, and analysis, considered in the light of five tsunamis that have struck Japan and Indonesia in the last two decades: the 2004 Indian Ocean tsunami; the 2011 Great East Japan tsunami; the 2016 Fukushima tsunami; and the 2018 Sulawesi tsunami and the 2018 Sunda Strait tsunami in Indonesia. Progress in tsunami risk understanding and awareness is evaluated based on the approaches presented in the SFDRR, especially Priority 1: Understanding disaster risk; and Priority 2: Strengthening disaster risk governance to manage disaster risk; as well as Global Targets (a) Substantially reduce global disaster mortality; and (g) Substantially increase the availability of, and access to, multi-hazard early warning systems and disaster risk information and assessments to the people (UNISDR 2015).

With a complex, long-term, and ongoing recovery, the case of the GEJE highlights the connections and relationships between DRR and recovery and the implications for resilient outcomes. Considered in light of the Sendai Framework, the discussion of recovery focuses on the guidelines in SFDRR Priority 4: Enhancing disaster preparedness for effective response and to "Build Back Better" in recovery, rehabilitation and reconstruction. For both the tsunami risk reduction and recovery perspectives, lessons learned from the GEJE are considered in the context of previous as well as subsequent events. The situation and progress are evaluated based on the Priorities and Global Targets of the SFDRR. Lessons from the GEJE from both the perspectives of (1) pre-disaster tsunami hazard risk; and (2) post-disaster recovery and vulnerability are considered in terms of the seven global targets to clarify the current situation and progress.

\section{The Sendai Framework and Tsunami Engineering for Risk Reduction}

To consider what progress has been made towards the SFDRR's goals from the tsunami hazard risk engineering perspective, this section evaluates improvements and limitations in hazard engineering after the Great East Japan Earthquake, using the global targets of the SFDRR. Efforts to address tsunami hazards focus on (1) hazard warning; (2) mapping; and (3) risk assessment.

\subsection{Tsunami Observation and Warning Systems}

Tsunami detection, early warning, and evacuation are related to SFDRR Priority 1 Paragraph 24(c) that aims to "develop, periodically update and disseminate, as appropriate, location-based disaster risk information, including risk maps," and Priority 1 Paragraph 24(f) using real-time data to do so. Based on the GEJE experience, Japan revised several aspects of the tsunami warning system and increased the number of offshore sensors that can detect tsunami activity. However, the 2016 Fukushima tsunami and the two tsunamis that occurred in Indonesia in 2018 showed limitations for detecting and disseminating warning information for tsunamis caused by non-seismic disturbances such as volcanic eruptions or underwater landslides and not directly by undersea earthquakes.

\subsubsection{New Dense Tsunami Observation System}

At the time of the GEJE, the number of offshore GPS observation buoys was limited. To allow more warning and evacuation lead time, Japan has developed a new real-time tsunami observation system "S-net" (Aoi et al. 2019), deploying 150 new tsunami sensors along the Tohoku coast extending to the Japan Trench and its eastern part to respond to outer-rise earthquakes. The Japan Meteorological Agency (JMA) is required to issue the initial tsunami warning within 3 minutes (JMA 2019b). It is expected that using S-net will significantly improve the accuracy of subsequent warning messages. Information from S-net is currently used in many research projects that are creating predictions of real-time tsunami inundation maps to be sent to residents in advance. The S-net system is also very useful for non-seismic tsunamis (like the 2018 Sulawesi tsunami and the 2018 Sunda Strait tsunami) because all other current tsunami warning systems around the world rely on assumed earthquake sources and related fault parameters (Suppasri et al. 2016).

After the GEJE, it seemed that the east coast of Japan was much better prepared for tsunamis and that S-net represented significant improvements in tsunami warning accuracy. However, the 2016 Fukushima tsunami demonstrated the limitations of S-net, because the epicenter was in a shallow area between the shallowest S-net sensor and land, outside the coverage area. In addition, the JMA's assumed fault parameter (fault orientation) used in the precalculated tsunami warning database differed from what actually happened (Suppasri et al. 2017), causing an underestimation of tsunami height. After the 2016 Fukushima tsunami, the JMA investigated other potential 
earthquakes near this area and updated the fault parameters used in the tsunami database.

At the time of the 2016 Fukushima tsunami, the JMA initially issued a "tsunami advisory" but the warning level was suddenly increased to "tsunami warning" two hours later. The JMA's own evaluation acknowledged that this situation is very rare (Suppasri et al. 2017). This was also the first tsunami warning issued since the GEJE. With no guidelines for this situation, local municipalities were unsure if they should remain at the advisory level or move to the warning level. They each made their own decision, leading to confusion for local governments and residents. Miyagi Prefecture has since revised its emergency plan to include this scenario.

\subsubsection{Revision of Tsunami Warning Levels and Warning Messages}

To simplify the complicated system of eight tsunami warning levels that existed in 2011, warning levels in Japan were reduced to five levels. It was also decided that warnings will be issued for "tsunami" or "large tsunami," rather than exact estimated tsunami heights, to avoid comparisons between heights of tsunami and ground elevation or seawalls, leading to delays or failures of evacuation. A new type of warning called "emergency warning" was also created, which requires coastal residents to evacuate in the case of a three meter or higher tsunami (JMA 2019a). Some aspects of risk communication still need improvement to ensure that local people can correctly understand complex scientific information and respond appropriately (see also Marchezini 2020).

\subsubsection{Future Challenges for Non-Seismic Tsunamis}

Two non-seismic tsunamis that occurred in Indonesia in 2018 showed other existing problems related to these unusual tsunamis, which have complex generating mechanisms and are very rare and hard to predict. The 2018 Sulawesi tsunami was caused by a strike-slip earthquake with a magnitude of 7.4. Although strike-slip earthquakes (horizontal movement) are generally understood not to generate large tsunamis, the earthquake caused aerial (land into the sea) and submarine (undersea) landslides and several local tsunamis that killed more than 2000 people (Pakoksung et al. 2019). One tide gauge station near the epicenter recorded a large tsunami that arrived after five minutes but this information could not be seen or used for proper warning messages because of power failures.

Another non-seismic tsunami, the 2018 Sunda Strait tsunami, was generated by a large-scale flank collapse after the eruption of the Anak-Krakatoa volcano, causing human casualties and extensive damage to Sumatra and Java islands (Syamsidik et al. 2019). With no early natural warnings such as strong ground shaking as in an earthquake, no tsunami warning was issued. Currently, the Indonesian government is considering the deployment of more tsunami observation sensors and strengthening tsunami education to improve coastal evacuation.

\subsection{Tsunami Hazard Assessment and Tsunami Hazard Maps}

This section considers the creation of risk maps, called for in Priority 1 Paragraph 24(c), and introduces several initiatives that improve the accuracy of tsunami modeling data and estimations. However, even with increased accuracy, uncertainties and various limitations remain, depending on local and national contexts. Although the SFDRR calls for sharing disaster data widely, practical limitations include not only the quality of the available data, but also the fact that sharing data is voluntary.

\subsubsection{Global Tsunami Model (GTM) and Probabilistic Tsunami Hazard Analysis (PTHA)}

The Global Tsunami Model (GTM) was established in 2015 (GTM 2019), similar to the previously established Global Earthquake Model (GEM) and the Global Volcano Model (GVM). The GTM comprises global tsunami expertise from various fields, including tsunami source determination, tsunami hazard and risk assessment, and knowledge dissemination. Toward the goal of the GTM to establish a global standard for Probabilistic Tsunami Hazard Analysis (PTHA) and the results of risk assessments, more research is still needed on some topics, such as the understanding of non-seismic tsunamis and more detailed global risk assessments.

Based on new knowledge and information of tsunami sources from crustal movements, the use of PTHA contributes to improved understanding of tsunami deposits and earthquake sizes and their recurrence. Because of limitations of computational costs, the PTHA models offshore (50-100 m sea depth) tsunami amplitude based on future tsunami events, applying probabilistic methods. Probabilistic Tsunami Hazard Analysis provides information such as "an $n \mathrm{xxx} \mathrm{m}$ tsunami will repeatedly occur every roughly xxx years" or "within xxx years, about a xxx m tsunami is expected." Such information is important in designing heights of coastal defense structures and hazard risk areas for purposes of evacuation and land use planning. Shortly before and since the establishment of the Sendai Framework, a number of research projects have applied PTHA to tsunami assessment at a global scale (Davies et al. 2017), regionally in the Pacific (De Risi and Goda 2016) and Indian (Horspool et al. 2014) oceans, and locally 
(González et al. 2014). Nevertheless, PTHA contains uncertainties of earthquake sources, bathymetry data, and assumptions in numerical simulation. In addition, PTHA only provides offshore tsunami amplitudes from estimated earthquake scenarios. Inland tsunami inundation might be higher than that specified by PTHA, and non-seismic tsunamis might generate larger local tsunamis.

\subsubsection{Inland Tsunami Inundation Mapping}

Most tsunami hazard maps underestimated the areas affected by the GEJE. Updated hazard maps were created for the Tohoku area using the actual 2011 tsunami-inundated area. For other areas in Japan, earthquake sources were comprehensively recalculated with larger earthquakes to create new hazard maps. New tsunami hazard maps published after the GEJE were updated to include simulated flow velocity, inundation zones with different recurrence, and ground elevations (Fukutani et al. 2018). The main challenge for inundation mapping is the detailed topography and bathymetry data (that is, $10 \mathrm{~m}$ resolution or less) used for numerical simulation (Suppasri et al. 2016). While improved maps with greater accuracy can be seen as a good practice in Japan, in many countries such detailed data are not available or cannot be used or shared due to security or political issues.

\subsection{Tsunami Vulnerability Analysis and Risk Assessment}

Another facet of SFDRR Priority 1: Understanding disaster risk, is that the analyses of tsunami risk and vulnerability are key factors towards achieving the SFDRR Global Targets (a) Substantially reduce global disaster mortality by 2030; and (b) Substantially reduce the number of affected people globally by 2030. In terms of human damage and casualties after the 2004 Indian Ocean Tsunami and the $2011 \mathrm{GEJE}$, there have been advances in collecting and understanding relevant data, in line with SFDRR Priority 4 Paragraph 33(n) "To establish a mechanism of case registry and a database of mortality caused by disaster in order to improve the prevention of morbidity and mortality," including sex-disaggregated data as called for by SFDRR Guiding Principle (g).

\subsubsection{Human Casualties}

Research on the relationship between tsunami characteristics and human casualties and building damage was substantially advanced after the 2004 Indian Ocean tsunami. Information about lives lost in Banda Aceh, Indonesia was collected at the village level, and casualty ratios for each village were calculated using population data. Fragility functions for human fatalities were developed by compiling casualty ratios and simulated tsunami flow depth (Koshimura et al. 2009). For the GEJE, more detailed casualty data were collected up to street level, with other information such as sex and age that allows further investigation of this relationship between the location of casualties and the depth of the tsunami in that location (Latcharote et al. 2018). A new project on this issue was started in 2018 using detailed death data provided by the Miyagi Prefectural Police. These data contain personal information (sex and age), residential address, and locations where bodies were found, as well as under what conditions (inside a car, in the sea, and so on). Used to clarify causes of death (Seto et al. 2019), these data are geospatially compiled with tsunami characteristics and other parameters for further investigation. Through this improved understanding, better ways of saving lives from tsunamis can be proposed.

\subsubsection{Tsunami Simulation Techniques and Damage Estimates}

Relationships between simulated tsunami flow depth, flow velocity, and hydrodynamic forces against building damage ratio were used to empirically develop tsunami fragility functions in Indonesia (Koshimura et al. 2009) and Thailand (Suppasri et al. 2011). Because of the limited level of detail of the survey data, various fragility functions for different building types could not be developed. After the GEJE, very detailed building damage surveys allowed for the development of tsunami fragility functions with different building materials, numbers of floors, construction years, and functions (house, apartment, shop, school, hospital, and so on) (Suppasri et al. 2015a). In this sense, the new tsunami fragility functions allow increasingly accurate damage assessments that can be used for further loss assessment and urban planning purposes. Challenges remain for applying the developed tsunami fragility functions to future tsunamis in other areas, as building materials or construction types differ by country. Current attempts to solve such issues include numerical (Park et al. 2012) and analytical methods (Gentile et al. 2019; Suppasri et al. 2019) directly using tsunami and building resistance forces to assess building damage. In addition to buildings, other tsunami fragility functions were developed for bridges (Shoji and Nakamura 2017), for the first time using detailed damage data of the 2011 tsunami, as well as for marine vessels (Suppasri et al. 2014; Muhari et al. 2015), aquaculture rafts and eelgrasses (Suppasri et al. 2018a), and fishery port facilities (Imai et al. 2019).

In 2004, tsunami simulation techniques only allowed for the simulation of tsunami waves. Since then, especially with better data for verification after 2011, improved 
computational environments have made it increasingly possible to integrate sediment transport modeling, debris flow modeling, and tsunami fire modeling into the original tsunami modeling. Such improvements contribute to understanding the whole tsunami risk.

\subsection{Reflections on the Sendai Framework Global Targets as Applied to Progress in Tsunami Engineering}

Advancements in engineering approaches to address tsunami hazards and vulnerabilities and their contributions to the Sendai Framework global targets are summarized in Table 1.

Tsunami observation and warning systems, a focus of Global Target (g) (increasing the availability of, and access to, multi-hazard early warning systems and disaster risk information and assessments), were much improved after the GEJE, not only in Japan but also in other countries such as Indonesia, which suffered non-seismic tsunamis in 2018. Improvements of observation and warning systems also contribute to Global Targets (a) (reducing disaster mortality) and (b) (reducing the number of people affected by disasters).

Improved accuracy of PTHA results and hazard maps contribute to Global Targets (c) (reducing direct economic loss) and (d) (reducing damage to critical infrastructures and facilities). By understanding this contextual information, residential and critical facilities can be moved to safe areas where appropriate countermeasures can be applied to critical infrastructure. Better hazard assessment results also contribute to reductions in mortality (Global Target (a)) and affected people (Global Target (b)) as coastal residents have information of safe evacuation routes and shelters.

A number of studies on tsunami vulnerability analysis in terms of tsunami fragility functions have greatly contributed to Global Targets (a), (c), (d), and (g). For example, zones excluding residential use can be decided based on human casualty ratios; the identification of areas with short tsunami arrival times and large vulnerable populations points out where early warning and monitoring should be strongly implemented (see also New Zealand's approach in Saunders et al. 2020). Using fragility functions that correlate tsunami parameters such as estimated flow depth with damage ratio criteria, as suggested in the SFDRR, critical infrastructure and facilities can be reconsidered or relocated. As the SFDRR only suggests criteria such as the damage ratio of buildings and/or infrastructure, fragility functions that also correlate these ratios to tsunami parameters such as flow depth demonstrate practical applications that, while linked to the goals of the SFDRR, go beyond what the Sendai Framework prescribes.

\section{The Sendai Framework and Post-Disaster Recovery and Vulnerability}

In addition to pre-disaster hazard mitigation efforts, the SFDRR brings a new emphasis to risk reduction in the post-disaster recovery phase. While the primary goal of this framework is mitigating future disaster losses, the SFDRR has significant implications for post-disaster recovery, both through its overall approach and specific topics related to reconstruction. Although it is not a framework for good recovery practices per se, these are directly supported by the people-centered approach of the SFDRR, which recognizes the holistic nature of people's lives and disasteraffected communities and the broader disaster impacts on livelihood and health, underscored by an emphasis on inclusivity.

The SFDRR addresses several topics directly related to recovery, including the elevation of Build Back Better to a primary position in Priority 4. Additionally, specific mentions of reconstruction topics include: pre-disaster recovery planning; a need for knowledge sharing on recovery; land use planning; and the reconstruction of critical community resources and infrastructure. This section considers postdisaster aspects of the SFDRR related to vulnerability, with a specific focus on the term Build Back Better in the context of international recovery discourse and cases, illustrated by the application of these ideas to the ongoing recovery after the Great East Japan Earthquake.

\subsection{Build Back Better (BBB)}

Priority 4 of the SFDRR, "Enhancing disaster preparedness for effective response and to 'Build Back Better' (BBB) in recovery, rehabilitation and reconstruction," states that "the recovery, rehabilitation and reconstruction phase is a critical opportunity to build back better, including through integrating disaster risk reduction into development measures" (UNISDR 2015). Along with other agencies and organizations using it as the goal for recovery, United Nations Special Envoy for Tsunami Recovery Bill Clinton called for "Building Back Better" in the recovery of affected areas two years after the 2004 Indian Ocean Tsunami (Clinton 2006; James Lee Witt Associates 2005). In the years since, BBB has been increasingly used to describe goals for a recovery that improves conditions in affected areas, improves disaster risk reduction, or generally promotes good practices in recovery (Fan 2013). Both before and after featuring prominently in the Sendai Framework, BBB was highlighted as the goal of national disaster recovery plans following the 2005 Pakistan Earthquake (Fan 2013) and the 2015 Nepal Earthquake (Government of Nepal National Planning Commission 
Table 1 Tsunami engineering with respect to hazards and vulnerabilities and its contribution to the Sendai Framework global targets

\begin{tabular}{llllllll}
\hline SFDRR Global Targets & $\mathrm{a}$ & $\mathrm{b}$ & $\mathrm{c}$ & $\mathrm{d}$ & $\mathrm{e}$ & $\mathrm{f}$ & $\mathrm{g}$ \\
\hline 3.1 Observation and early & $\bigcirc$ & $\triangle$ & & & & & $\bigcirc$ \\
$\quad$ warning & & & & & & & \\
3.2 Hazard assessment & $\triangle$ & $\triangle$ & $\bigcirc$ & $\bigcirc$ & & & \\
3.3 Vulnerability analysis & $\bigcirc$ & $\triangle$ & $\bigcirc$ & $\bigcirc$ & & & \\
\hline
\end{tabular}

$O=$ Direct contribution and $\triangle=$ indirect contribution

2015). After 2013 Typhoon Yolanda, BBB featured prominently in the Philippines' recovery plan "Build Back Better: Reconstruction Assistance on Yolanda (RAY)," which called for stronger housing that is able to withstand storms, along with the creation of no-build zones to prevent people from rebuilding in hazardous areas (NEDA 2013). As its use became ubiquitous, BBB was used to describe a wide variety of development aims from peace-building in post-conflict Aceh and Sri Lanka to sustainability and livelihood recovery in post-Cyclone Nargis Myanmar, and in Haiti for programs unrelated to earthquake recovery (Fan 2013).

Although used earlier, the popularity of the term Build Back Better in the mainstream international discourse of DRR grew significantly following 2006, when Clinton's Propositions for recovery included Proposition \#10: "Good recovery must leave the community safer by reducing risk and building resilience" (Clinton 2006). Through an analysis of all 10 of Clinton's principles, Kennedy et al. (2008) posit the meaning of BBB as "build back to a less vulnerable state than before." In response to the confusing multiple meanings used for BBB, Kennedy et al. (2008) suggested the phrase "building back safer" may be more appropriate; their interpretation of safer includes a broad idea of reduced vulnerability and improvements for people's lives (Maly 2017). Fan (2013) called for a clear distinction between "build back safer," defined by a narrow focus on technical interpretations of single facets like physical building structure, and "build back better" that transcends technical fixes to transform social and political power relations (Maly 2017). In this way, a number of authors have raised concerns about potential negative impacts of projects implemented in the name of building back "safer" or "better," lacking a holistic consideration of what is "better" for affected people, including complex impacts of multiple facets (Monday 2002; Kennedy et al. 2008; Fan 2013; Maly 2017). As Monday (2002, p. 2) cautioned, building back better should not "consider hazard mitigation in isolation from other aspects of community building," and ensure efforts "to protect from hazards are not just creating burdens for someone else." Kennedy et al.
(2008, p. 33) also emphasized that recovery "should not address one hazard at the expense of another," giving the example of a buffer zone created to reduce risk and build back better, but that may result in the opposite as destruction of livelihood leads to greater vulnerability.

The prominence gained by BBB through the Sendai Framework has increased the potential for the idea of BBB to be used in a narrow definition as structural solutions for reducing risk without fully considering if outcomes are indeed better for the people involved. Recognizing the primacy of $\mathrm{BBB}$ as promoted by the Sendai Framework, the Global Facility for Disaster Reduction and Recovery (GFDRR) has attempted to provide a more nuanced consideration in "Building Back Better: Achieving Resilience through Stronger, Faster, and more Inclusive Post-Disaster Reconstruction" (GFDRR 2018), in which BBB is described as being composed of three aspects: building back stronger, faster, and more inclusively. While a focus on stronger recovery in $\mathrm{BBB}$ is not new, clarifying building back stronger as one of several aspects of BBB speaks to the issues raised by Kennedy et al. (2008) and Fan (2013). Equating building back faster with building back better may be an oversimplification, as trade-offs between speed and deliberation in the recovery processes mean that faster may not be better in terms of recovery (Olshansky and Johnson 2010; Platt and So 2017). The focus on "building back more inclusively" as one of the main three dimensions of $\mathrm{BBB}$ is a significant advancement in addressing issues of an overly narrow focus of $\mathrm{BBB}$ on physical or technological safety (Fan 2013; Maly 2017) and the troubling promotion of top-down technological advances at the expense of community-level input (Tozier de la Poterie and Boudoin 2015).

\subsection{Building Back Better after the Great East Japan Earthquake}

Created a month after the GEJE, in June 2011 Japan's Reconstruction Design Council issued the document "Toward Reconstruction: Hope beyond the Disaster" (Reconstruction Design Council, Government of Japan 2011; Iuchi et al. 2015), laying out the national vision for recovery. The strategies included the combination of structural and nonstructural measures to rebuild the affected areas of Tohoku with reduced tsunami risk, such as through the construction of seawalls and levees, and residential relocation to high-ground areas. Although issued as guidelines, the schematic methods (mountain cutting, land raising, levee defenses) were applied in various combinations for recovery projects in affected municipalities, who prepared town recovery plans utilizing projects from a menu of reconstruction projects fully funded by the national government. 
In the aftermath of the massive and devastating tsunami, the Japanese government made a strong commitment to rebuilding the affected region to a high level of safety. Based on simulations of future tsunami heights, massive infrastructure projects have been carried out in the region, including the construction of huge seawalls and levees, hardened riverbanks and levees, and new and/or elevated roads and highways. Recovery planning for tsunami-affected communities was carried out based on calculations of future tsunami inundation, designating many areas, formerly dense mixed-use residential and commercial communities before the tsunami, as hazardous areas where future residential use is forbidden. Most towns also used other recovery projects to provide new residential lots in higher and/or inland areas for people to rebuild their houses, along with provision of rental disaster recovery public housing units for residents who could not or did not want to finance and/or manage the rebuilding of their own houses.

These recovery plans and programs carried out in municipalities along the Tohoku coastline include several aspects of recovery specifically mentioned in the SFDRR, such as: land use planning in Priority 4 Paragraphs $33(\mathrm{j})$ and $33(\mathrm{k})$; relocation of public facilities and infrastructure outside of the hazardous areas in Priority 4 Paragraph 33(1); and resilience of new and existing critical infrastructure, including water, transportation and telecommunications infrastructure, educational facilities, hospitals and other health facilities, in Priority 4 Paragraph $33(\mathrm{c})$.

Other aspects promoted in the SFDRR can be considered partially achieved in the post-GEJE recovery. Along with efforts to address these issues, significant unresolved challenges and unaddressed needs remain, including: enhancing recovery schemes to provide psychosocial support and mental health services for all people in need, Priority 4 Paragraph 33(o). While understanding the importance of psychosocial care in Japan has greatly improved based on lessons from the 1995 Great Hanshin Awaji Earthquake in Kobe, and government and nonprofit/ volunteer organizations tried to provide many activities and support for disaster survivors (Tanisho et al. 2015), there remained unaddressed needs for evacuees' mental health care, and especially for elderly survivors. One example is the issue of kodokushi (solitary death), when a person passes away completely isolated from society, to the point that no one notices their death, which is only reported later when their body is discovered. With links to alcoholism and/or suicide, this phenomenon was already well-known after the 1995 Kobe earthquake (Ranghieri and Ishiwatari 2014), yet it continues in Tohoku, where more than 200 people have died solitary deaths since the 2011 disaster as of September 2019 (Mainichi Shinbun 2019). As understood from the experience in Kobe, the number of kodokushi grows as people move from temporary to permanent housing and become more isolated in the process. There are also aspects promoted in the SFDRR that are missing from the recovery after the GEJE, including: empowering women and persons with disabilities to publicly lead and promote gender equitable and universally accessible approaches, Priority 4 Paragraph 32 (see also Bennett 2020). Table 2 lists the aspects of Priority 4 and their implementation in the recovery after the GEJE.

Beyond these individual aspects, the massive modifications of townscapes and landscapes, displacement, and disruptions and relocation of communities and neighbors may result in negative impacts on the affected region that are not yet understood. This kind of large-scale coastal retreat as part of residential relocation, at a scale difficult to implement in a country without the strong governance of Japan, can be understood as building back better based on the narrowest interpretation of the term-rebuilding with reduced risk to a specific hazard. However, it is not so easy to say decisively that this is really building back better for the affected residents, or considering the long-term future sustainability of communities and the region.

\subsection{Additional Challenges of Post-Nuclear Recovery in Fukushima}

One of the key new additions to the SFDRR is the inclusion of technological disasters as well as disasters involving natural hazards. After the nuclear meltdown at the Fukushima Daiichi Nuclear Power Plant, nuclear evacuees face long-term displacement, confusion, and uncertainty regarding their former towns and future lives. A group of nongovernmental organizations and researchers collaborated to share the lessons of Fukushima with a global audience at the 2015 World Conference of Disaster Risk Reduction. They compiled a clear synthesis of the challenges in Fukushima based on the seven global targets of the SFDRR in "Japan's Dilemma: Nuclear Power Plant Accident and Implementation of Sendai Framework for DRR," also known as the Fukushima Booklet (Fukushima Booklet Committee 2018). The multiple critical failures in meeting the SFDRR's goals in Fukushima, presented as dilemmas, include the rising number of indirect deaths although one global target is reducing mortality, as well as the long-term impacts on people and the economy, from the lack of critical community infrastructure like schools and hospitals, and from the persistence of non-functioning early warning systems (Fukushima Booklet Committee 2018) (Table 3). 
Table 2 Evaluation of the Great East Japan Earthquake recovery by initiatives promoted in Sendai Framework Priority 4

\begin{tabular}{ll}
\hline Initiative & Implementation \\
\hline Land use planning & Strong \\
Relocation of public facilities/infrastructure out of hazardous areas & Strongly enforced \\
Resilience of new and existing critical infrastructure & Strong \\
Psychosocial support and mental health services & Somewhat \\
Empowering women and persons with disabilities & Lacking \\
\hline
\end{tabular}

Table 3 "Dilemmas" in Fukushima—contradictions between the Sendai Framework's global targets and the reality (Fukushima Booklet Committee 2018)

Sendai Framework Global Targets

(a) Reduce mortality
(b) Reduce number of affected people
(c) Reduce economic loss
(d) Reduce damage to basic services, health and
educational facilities
(e) Increase the disaster risk reduction strategies
(f) Enhance international cooperation
(g) Increase availability/access to early warning systems

\section{Dilemma}

Indirect/related deaths $2000+$

Ongoing/long-term disaster impacts/displacement

Huge costs for decontamination

Lack of hospitals and schools

Restarting nuclear plants without disaster risk reduction

Japan still exporting nuclear power plants

The System for Prediction of Environment Emergency Dose Information (SPEEDI) did not function

Table 4 Great East Japan Earthquake recovery contribution to the Sendai Framework global targets

\begin{tabular}{lllllll}
\hline Sendai Framework Global Targets & a & b & c & d & e & f \\
\hline Reducing direct risk of natural hazard impacts in the future & $\bigcirc$ & $\bigcirc$ & $\bigcirc$ & $\bigcirc$ & $\bigcirc$ & $\bigcirc$ \\
Impact on peoples' lives post-disaster & $\triangle$ & $\triangle$ & $\triangle$ & $\triangle$ & $\bigcirc$ & $\triangle$ \\
Impact on peoples' lives post-disaster in Fukushima & X & $X$ & $X$ & $\bigcirc$ & $\triangle$ & $\triangle$ \\
\hline
\end{tabular}

$O=$ Positive impact, $\Delta=$ partial or mixed impact, $X=$ negative impact

\subsection{Sendai Framework Global Targets as Applied to Recovery after the Great East Japan Earthquake}

Evaluation of progress in post-GEJE recovery sharply diverges depending on the framing of the SFDRR global targets. Simply considering reduced damage to life and property in the case of a future tsunami event, reconstruction measures that focus on massive infrastructure projects and enforced coastal retreat may be seen as successfully achieving recovery-related targets of the SFDRR. However, these drastic changes in the affected areas may have negative effects on the life recovery and long-term sustainability of local communities - which can be considered "building back better for people." This disparity becomes more severe when considering the impact on affected communities in Fukushima and dealing with longterm issues (Table 4).
As indirect and solitary deaths continue (a), people remain affected (b), and there are economic impacts (c). In tsunami-affected areas, new improved health and education facilities replace temporary disruptions (d), but not necessarily in Fukushima. This disparity demonstrates that a simple focus on building back "safer" for the next disaster does not address all existing needs in the recovery phase. A stronger synergy is needed between building back better for people and risk reduction principles.

\section{Conclusion}

The case of the Great East Japan Earthquake and Tsunami of 2011 illustrates advances and limitations in pre-disaster tsunami hazard engineering and post-disaster recovery measured against the priorities and targets of the Sendai Framework, which represents an inclusive approach to 
DRR integrated with disaster recovery and development. With respect to the goals of the SFDRR for risk reduction, especially Priority 1, understanding disaster risk, there have been significant advances in tsunami observation and warning systems, although challenges remain. Improved accuracy of hazard and vulnerability assessments reduces damage and loss, along with ongoing advances in analysis. Although the SFDRR emphasizes actions in the recovery phase through Priority 4 and Build Back Better, this does not provide as clear a directive for evaluating recovery. Although the SFDRR emphasizes the importance of building back better, the vagueness inherent in this concept and its use limit its effectiveness as an objective measure of recovery success. However, the overall people-centered and inclusive approach of the SFDRR, as well as the global targets and several sub-priorities, can be a useful way to shape good practices in recovery and evaluate recovery progress. By considering them through the lens of the priorities and targets of the SFDRR, lessons from the GEJE can be understood in terms of what progress has been made and what challenges still remain. As recovery after the GEJE is ongoing and the SFDRR is only five years old, significant potential remains for deeper and more detailed future analysis of the GEJE in the international context using the Sendai Framework.

Acknowledgments This research was supported by the Core Research Cluster of Disaster Science in Tohoku University (Designated National University), Tokio Marine \& Nichido Fire Insurance Co., Ltd., and Willis Research Network (WRN).

Open Access This article is licensed under a Creative Commons Attribution 4.0 International License, which permits use, sharing, adaptation, distribution and reproduction in any medium or format, as long as you give appropriate credit to the original author(s) and the source, provide a link to the Creative Commons licence, and indicate if changes were made. The images or other third party material in this article are included in the article's Creative Commons licence, unless indicated otherwise in a credit line to the material. If material is not included in the article's Creative Commons licence and your intended use is not permitted by statutory regulation or exceeds the permitted use, you will need to obtain permission directly from the copyright holder. To view a copy of this licence, visit http://creativecommons. org/licenses/by/4.0/.

\section{References}

Aitsi-Selmi, A., S. Egawa, H. Sasaki, C. Wannous, and V. Murray. 2015. The Sendai framework for disaster risk reduction: Renewing the global commitment to people's resilience, health, and well-being. International Journal of Disaster Risk Science 6(2):164-174.

Aoi, S., W. Suzuki, N. Chikasada, T. Miyoshi, T. Arikawa, and K. Seki. 2019. Development and utilization of real-time tsunami inundation forecast system using s-net data. Journal of Disaster Research 14(2): 212-224.

Bennett, D. 2020. Five years later: Assessing the implementation of the four priorities of the Sendai framework for inclusion of people with disabilities. International Journal of Disaster Risk Science. https://doi.org/10.1007/s13753-020-00267-w.

Cabinet Office. 2015. White paper: Disaster management in Japan 2015. https://www.bousai.go.jp/kyoiku/panf/pdf/WPDM2015_ Summary.pdf. Accessed 3 Apr 2020.

Clinton, W.J. 2006. Lessons learned from tsunami recovery: Key propositions for building back better, United Nations SecretaryGeneral's special envoy for tsunami recovery. New York: United Nations.

Davies, G., J. Griffin, F. Løvholt, S. Glimsdal, C.B. Harbitz, H.K. Thio, S. Lorito, R. Basili, et al. 2017. A global probabilistic tsunami hazard assessment from earthquake sources. Geological Society London Special Publications 456(1): 219-244.

De Risi, R., and K. Goda. 2016. Probabilistic earthquake-tsunami multi-hazard analysis: Application to the Tohoku region, Japan. Frontiers in Built Environment 2: Article 25. doi:10.3389/ fbuil.2016.00025.

Fan, L. 2013. Disaster as opportunity? Building back better in Aceh, Myanmar and Haiti. London: Overseas Development Institute.

Fukushima Booklet Committee. 2018. Japan's Dilemma: Nuclear power plant accident and implementation of Sendai Framework for DRR. https://jcc-drr.net/wpJD/wp-content/uploads/2018/07/ Japans-Dilemma.pdf. Accessed 3 Apr 2020.

Fukutani, Y., A. Suppasri, and F. Imamura. 2018. Quantitative assessment of epistemic uncertainties in tsunami hazard effects on building risk assessments. Geosciences 8(1): Article 17.

Gentile, R., C. Galasso, Y. Idris, I. Rusydy, and E. Meilianda. 2019. From rapid visual survey to multi-hazard risk prioritisation and numerical fragility of school buildings. Natural Hazards and Earth System Sciences 19(7): 1365-1386.

GFDRR (Global Facility for Disaster Reduction and Recovery). 2018. Building back better: Achieving resilience through stronger, faster, and more inclusive post-disaster reconstruction. Washington, DC: GFDRR.

González, F.I., R.J. LeVeque, L.M. Adams, C. Goldfinger, G.R. Priest, and K. Wang. 2014. Probabilistic Tsunami Hazard Assessment (PTHA) for Crescent City, CA. Final report for phase I. https://digital.lib.washington.edu/researchworks/handle/ 1773/22366?show=full. Accessed 18 Nov 2019.

Government of Nepal National Planning Commission. 2015. Post disaster needs assessment. Kathmandu: Government of Nepal National Planning Commission.

GTM (Global Tsunami Model). 2019. Global Tsunami Model. https:// edanya.uma.es/gtm/. Accessed 18 Nov 2019.

Horspool, N., I. Pranantyo, J. Griffin, H. Latief, D.H. Natawidjaja, W. Kongko, A. Cipta, B. Bustaman, et al. 2014. A probabilistic tsunami hazard assessment for Indonesia. Natural Hazards and Earth System Sciences 14(11): 3105-3122.

IDNDR (International Decade for Natural Disaster Reduction). 1994. Yokohama strategy and plan of action for a safer world: Guidelines for natural disaster prevention, preparedness and mitigation. https://www.unisdr.org/we/inform/publications/8241. Accessed 4 Apr 2020.

Imai, K., T. Inazumi, K. Emoto, T. Horie, A. Suzuki, K. Kudo, M. Ogawa, M. Noji, et al. 2019. Tsunami vulnerability criteria for fishery port facilities in Japan. Geosciences 9(10): Article 410.

Iuchi, K., E. Maly, and L. Johnson. 2015. Three years after a megadisaster: Recovery policies, programs and implementation after the Great East Japan Earthquake. In Post-tsunami hazard reconstruction and restoration, ed. V. Santiago-Gandino, Y.A. Kontar, and Y. Kaneda, 29-46. London: Springer.

James Lee Witt Associates. 2005. Building back better and safer: Private sector summit on post-tsunami reconstruction. Washington, DC: James Lee Witt Associates.

JMA (Japan Meteorological Agency). 2019a. Flow of issuance of information about tsunami and earthquake. https://www.data. 
jma.go.jp/svd/eqev/data/en/guide/info.html. Accessed 18 Nov 2019.

JMA (Japan Meteorological Agency). 2019b. Emergency warning system. https://www.jma.go.jp/jma/en/Emergency_Warning/ew_ index.html. Accessed 18 Nov 2019.

Kennedy, J., J. Ashmore, E. Babister, and I. Kelman. 2008. The meaning of 'build back better': Evidence from Post-Tsunami Aceh and Sri Lanka. Journal of Contingencies and Crisis Management 16(1): 24-36.

Koshimura, S., T. Oie, H. Yanagisawa, and F. Imamura. 2009. Developing fragility functions for tsunami damage estimation using numerical model and post-tsunami data from Banda Aceh, Indonesia. Coastal Engineering Journal 51(3): 243-273.

Latcharote, P., N. Leelawat, A. Suppasri, P. Thamarux, and F. Imamura. 2018. Estimation of fatality ratios and investigation of influential factors in the 2011 Great East Japan Tsunami. International Journal of Disaster Risk Reduction 29: 37-54.

Mainichi Shinbun. 2019. More than 200 solitary deaths in reconstructed housing in the 3 affected prefectures, measures need to prevent isolation, Great East Japan Earthquake. 9 September 2019. https://mainichi.jp/articles/20190909/k00/00m/040/ 318000c. Accessed 3 Apr 2020 (in Japanese).

Maly, E. 2017. Building back better with people centered housing recovery. International Journal of Disaster Risk Reduction 29: 84-93.

Marchezini, V. 2020. "What is a sociologist doing here?" An unconventional people-centered approach to improve warning implementation in the Sendai framework for disaster risk reduction. International Journal of Disaster Risk Science. https://doi.org/10.1007/s13753-020-00262-1.

Monday, J.L. 2002. Building back better: Creating a sustainable community after disaster. Natural Hazards Informer 3: 1-12.

Muhari, A., I. Charvet, T. Futami, A. Suppasri, and F. Imamura. 2015. Assessment of tsunami hazard in port and its impact on marine vessels from tsunami model and observed damage data. Natural Hazards 78(2): 1309-1328.

National Police Agency. 2019. Data on disaster victims as of December 2019. https://www.npa.go.jp/news/other/earth quake2011/pdf/higaijokyo.pdf. Accessed 3 Apr 2020 (in Japanese).

NEDA (National Economic and Development Authority). 2013. Reconstruction assistance on Yolanda: Build back better. Manila: NEDA. https://reliefweb.int/sites/reliefweb.int/files/ resources/20131216-RAY.pdf. Accessed 3 Apr 2020.

Olshansky, R.B., and L.A. Johnson. 2010. Clear as mud: Planning for the rebuilding of New Orleans. Chicago, IL: American Planning Association.

Pakoksung, K., A. Suppasri, F. Imamura, C. Athanasius, A. Omang, and A. Muhari. 2019. Simulation of the submarine landslide tsunami on 28 September 2018 in Palu Bay, Sulawesi Island, Indonesia, using a two-layer model. Pure and Applied Geophysics 176(8): 3323-3350.

Park, S., J.W. van de Lindt, D. Cox, R. Gupta, and F. Aguiniga. 2012. Successive earthquake-tsunami analysis to develop collapse fragilities. Journal of Earthquake Engineering 16(6): 851-863.

Platt, S., and E. So. 2017. Speed or deliberation: A comparison of post-disaster recovery in Japan, Turkey, and Chile. Disasters 41(4): 696-727.

Ranghieri, F., and M. Ishiwatari (eds.). 2014. Learning from megadisasters: Lessons from the great east Japan earthquake. Washington, DC: World Bank Group.

Reconstruction Agency. 2019a. Data of evacuees as of December 2019. https://www.reconstruction.go.jp/topics/main-cat2/subcat2-1/hinanshasuu.html. Accessed 3 Apr 2020 (in Japanese).

Reconstruction Agency. 2019b. Data of related deaths as of December 2019. https://www.reconstruction.go.jp/topics/main-cat2/sub- cat2-6/20191227_kanrenshi.pdf. Accessed 3 Apr 2020 (in Japanese).

Reconstruction Design Council, Government of Japan. 2011. Toward reconstruction: Hope beyond the disaster. Tokyo: Reconstruction Design Council, Government of Japan.

Saunders, W., S. Kelly, S. Paisley, and L. Clarke. 2020. Progress toward implementing the Sendai framework, the Paris agreement, and the sustainable development goals: Policy from Aotearoa New Zealand. International Journal of Disaster Risk Science. https://doi.org/10.1007/s13753-020-00269-8.

Seto, S., F. Imamura, and A. Suppasri, A. 2019. Challenge to build the science of human survival from disaster starting from analysis for the 2011 Tohoku Tsunami. Journal of Disaster Research 14(9): 1323-1328.

Shoji, G., and T. Nakamura. 2017. Damage assessment of road bridges subjected to the 2011 Tohoku Pacific earthquake tsunami. Journal of Disaster Research 12(1): 79-89.

Suppasri, A., S. Koshimura, and F. Imamura. 2011. Developing tsunami fragility curves based on the satellite remote sensing and the numerical modeling of the 2004 Indian Ocean tsunami in Thailand. Natural Hazards and Earth System Sciences 11(1): 173-189.

Suppasri, A., A. Muhari, T. Futami, F. Imamura, and N. Shuto. 2014. Loss functions of small marine vessels based on surveyed data and numerical simulation of the 2011 Great East Japan tsunami. Journal of Waterway, Port, Coastal and Ocean Engineering 140(5): Article 04014018.

Suppasri, A., I. Charvet, K. Imai, and F. Imamura. 2015a. Fragility curves based on data from the 2011 Great East Japan tsunami in Ishinomaki city with discussion of parameters influencing building damage Earthquake Spectra 31(2): 841-868.

Suppasri, A., K. Goto, A. Muhari, P. Ranasinghe, M. Riyaz, M. Affan, E. Mas, M. Yasuda, and F. Imamura. 2015b. A decade after the 2004 Indian Ocean tsunami - The progress in disaster preparedness and future challenges in Indonesia, Sri Lanka, Thailand and the Maldives. Pure and Applied Geophysics 172(12): 3313-3341.

Suppasri, A., P. Latcharote, J.D. Bricker, N. Leelawat, A. Hayashi, K. Yamashita, F. Makinoshima, V. Roeber, and F. Imamura. 2016. Improvement of tsunami countermeasures based on lessons from the 2011 great east japan earthquake and tsunami - Situation after five years. Coastal Engineering Journal 58(4): Article 1640011.

Suppasri, A., N. Leelawat, P. Latcharote, V. Roeber, K. Yamashita, A. Hayashi, H. Ohira, K. Fukui, A. Hisamatsu, D. Nguyen, and F. Imamura. 2017. The 2016 Fukushima Earthquake and Tsunami: Preliminary research and new considerations for tsunami disaster risk reduction. International Journal of Disaster Risk Reduction 21: 323-330.

Suppasri, A., K. Fukui, K. Yamashita, N. Leelawat, O. Hiroyuki, and F. Imamura. 2018a. Developing fragility functions for aquaculture rafts and eelgrass in the case of the 2011 Great East Japan tsunami. Natural Hazards and Earth System Sciences 18(1): $145-155$.

Suppasri, A., A. Muhari, Syamsidik, R. Yunus, K. Pakoksung, F. Imamura, S. Koshimura, and R. Paulik. 2018b. Vulnerability characteristics of tsunamis in Indonesia: Analysis of the Global Centre for Disaster Statistics. Journal of Disaster Research 13(6): 1039-1048.

Suppasri, A., K. Pakoksung, I. Charvet, C.T. Chua, N. Takahashi, T. Ornthammarath, P. Latcharote, N. Leelawat, and F. Imamura. 2019. Load-resistance analysis: An alternative approach to tsunami damage assessment applied to the 2011 Great East Japan tsunami. Natural Hazards and Earth System Sciences 19(8): 1807-1822. 
Syamsidik, Benazir, M. Luthfi, A. Suppasri, and K.L. Comfort. 2019. The 22 December 2018 Mount Anak Krakatau Volcanogenic Tsunami on Sunda Strait Coasts, Indonesia: Tsunami and damage characteristics. Natural Hazard and Earth System Sciences 20(2): 549-565.

Tanisho, Y., A. Smith, and H. Murakami. 2015. Post disaster mental health in Japan: Lessons and challenges. Tokyo: Health and Global Policy Institute.

Tozier de la Poterie, A., and M.A. Baudoin. 2015. From Yokohama to Sendai: Approaches to participation in international disaster risk reduction frameworks. International Journal of Disaster Risk Science 6(2): 128-139.
UNISDR (United Nations Office for Disaster Risk Reduction). 2005. Hyogo framework for action 2005-2015: Building the resilience of nations and communities to disasters. Geneva: UNISDR. https://www.unisdr.org/2005/wcdr/intergover/official-doc/Ldocs/Hyogo-framework-for-action-english.pdf. Accessed 3 Apr 2020.

UNISDR (United Nations Office for Disaster Risk Reduction). 2015. Sendai framework for disaster risk reduction 2015-2030, https:// www.unisdr.org/files/43291_sendaiframeworkfordrren.pdf. Accessed 1 Dec 2019.

UNDRR (UN Office for Disaster Risk Reduction). 2019. World tsunami awareness day. https://www.unisdr.org/tsunamiday. Accessed 18 Nov 2019. 